\title{
Spontaneous uterine rupture in primigravida at 15 weeks
}

\author{
Mousumi Das Ghosh*, Vinita Singh \\ Department of Obstetrics and Gynecology, Tata Main Hospital, Jamshedpur, Jharkhand, India
}

Received: 22 December 2016

Accepted: 20 January 2017

\section{*Correspondence:}

Dr. Mousumi Das Ghosh,

E-mail: dr.mousumi@tatasteel.com

Copyright: (C) the author(s), publisher and licensee Medip Academy. This is an open-access article distributed under the terms of the Creative Commons Attribution Non-Commercial License, which permits unrestricted non-commercial use, distribution, and reproduction in any medium, provided the original work is properly cited.

\begin{abstract}
This is a very rare and interesting case of primigravida with sonographic evidence of intrauterine pregnancy presenting with acute abdomen at 15 weeks. With the diagnosis of uterine rupture, emergency laparotomy was done. The defect was repaired and post-operative recovery was good. This shows that spontaneous uterine rupture can occur in primigravida and should be kept in mind during diagnosis of acute abdomen.
\end{abstract}

Key words: Primigravida, Spontaneous, Uterine rupture

\section{INTRODUCTION}

Uterine rupture in Primigravida is a very rare and one of the life threatening obstetrical emergencies. ${ }^{1}$ Usually, it is either associated with cases of trophoblastic tumor, or pathological invasion of the placenta through uterine wall, for example, placenta increta or percreta. ${ }^{2}$ It is commonly diagnosed with a history of previous scar on uterus, but rupture of uterus in a primigravida with no risk factors is extremely rare. ${ }^{3}$ We report a case of uterine rupture in primigravida who had no history of uterine surgeries. Underlying factor could not be identified.

\section{CASE REPORT}

Pinki Sonkar, 28 year old Primigravida was admitted in labour ward on 19.9.15 (Gestation age- 15 weeks) during emergency with pain abdomen and history of fainting attacks. She was admitted in nursing home $6 \mathrm{hrs}$ before, where she received i.v. fluids and analgesics and was referred to our centre. Her last menstrual period was on 6.6.15 Antenatal check-up was with a private practitioner. She was investigated for subfertility and conceived after ovulation induction. Hysterosalpingogram was done during work up for infertility which showed a normal uterine contour and bilateral free spill of dye on both sides. She had no past surgical interventions or uterine instrumentation. She was hypothyroid and was on Tab Thyroxine - 75 - OD.

Her baseline antenatal reports were normal. Ultrasound done at 8 weeks pregnancy confirmed intrauterine gestation with cardiac activity.

On examination, she was very pale with pulse rate of $140 / \mathrm{min}$ and blood pressure of $90 / 60 \mathrm{mmHg}$. Her abdomen was tender. Ultrasound examination showed bulky uterus with midline echo, free fluid in pouch of douglas, Sac with foetus outside uterus. Decision for emergency laparotomy was made.

Intraoperative findings were haemoperitoneum of 1.5litres along with $500 \mathrm{ml}$ of blood clots. Amniotic sac with a fully formed foetus was floating in the abdominal cavity. This got ruptured during delivery- clear fluid drained followed by foetus and placenta. Uterus was 10 weeks size, soft with rupture $6 \mathrm{~cm}$ long posteriorly on fundus extending transversely. The tear was repaired in layers. Both tubes and ovaries were healthy. She received 4 units packed cells and 4 units of Fresh frozen plasma. 
Post-operative recovery was good. The patient was discharged on fourth post-operative day. Since this was a rare diagnosis, $b$-hcG was requested on the day of surgery and the report was 2486 .

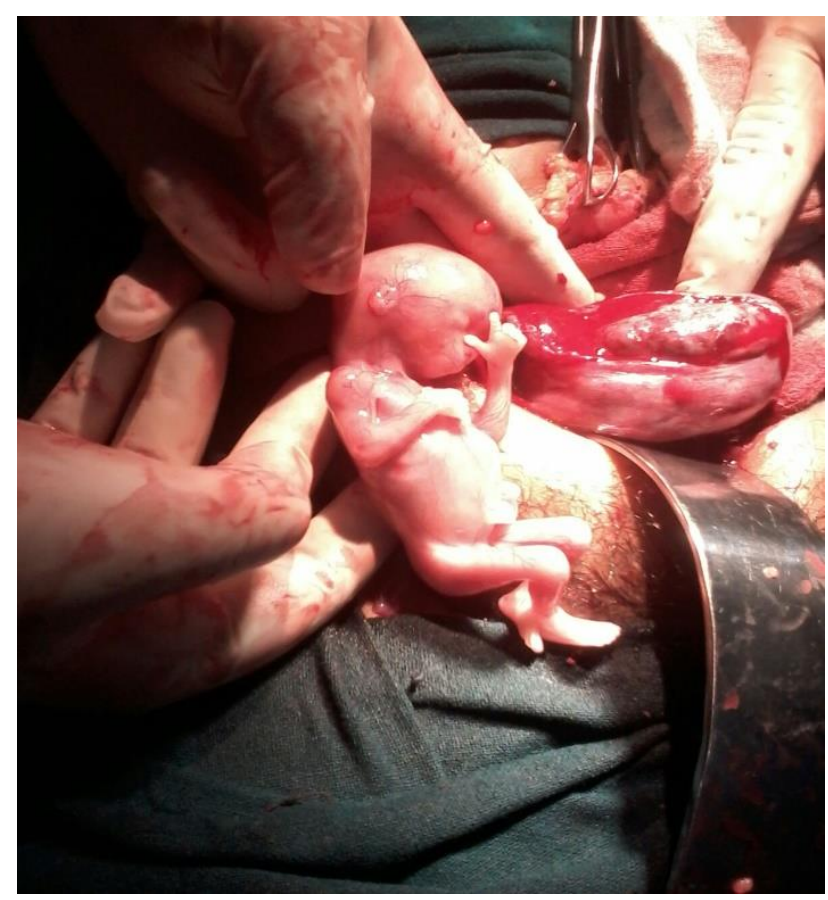

Figure 1: Picture showing uterine rupture and the expelled foetus.

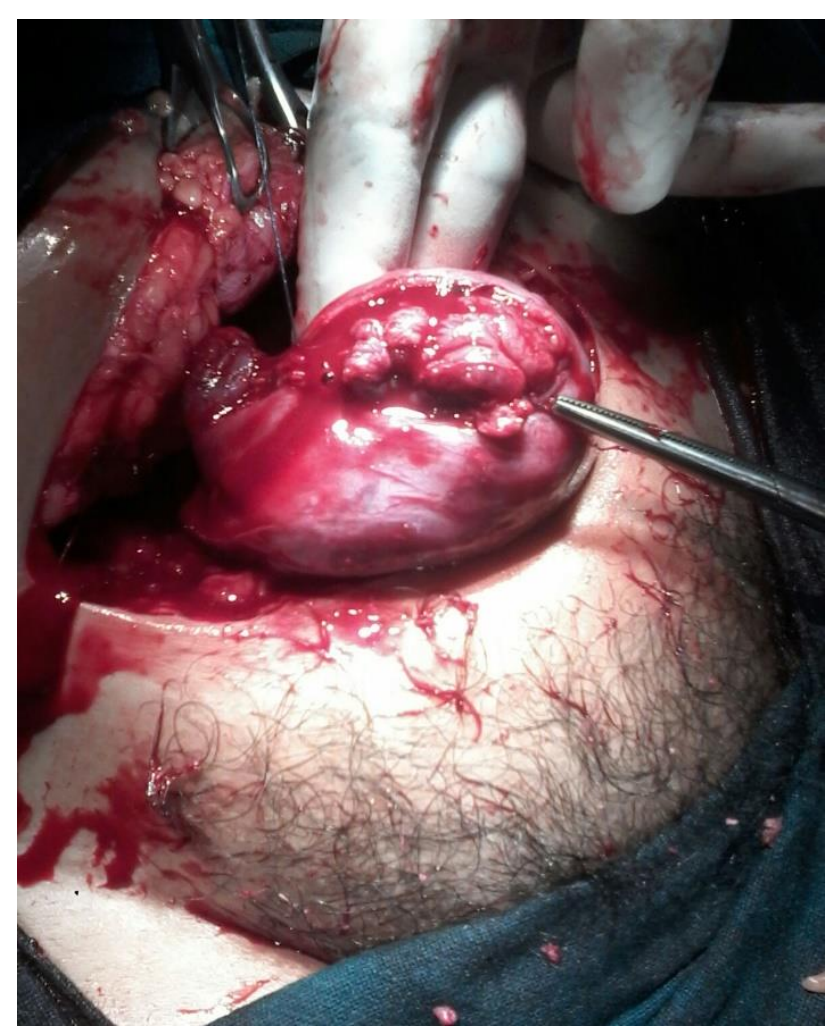

Figure 2: Picture showing repair of uterus

\section{DISCUSSION}

Uterine rupture is tearing of the uterine wall during pregnancy or delivery (WHO). It is one of the life threatening obstetric emergencies, with a significant effect on the reproductive function of woman. The overall rate of uterine rupture ranges from 1 in 1235 to 4366 , but the rate of primary uterine rupture are much lower and are estimated to range from 1 in 16,840 to 19,765 in the developed world. ${ }^{4}$ Uterus can rupture during pregnancy or delivery.

Most cases of rupture uterus occur during labour. Surgeries of upper segment of uterus like Hysterotomy, classical Caesarean section, myomectomy, previously repaired uterine rupture, metroplasty, and LSCS with inverted $\mathrm{T}$ shaped extension are more prone to uterine rupture early during pregnancy and at term. ${ }^{3}$

Risk factors for rupture uterus are multiparity, uterotonic drugs, placenta percreta, intrauterine manipulations such as internal podalic version, malpresentation, malposition, multiple pregnancy and perforation of uterus during MTP. Previous surgery on uterus like Caesarean Section, myomectomy, utriculoplasty is a strong risk factor for rupture uterus. Impaired collagen synthesis secondary to chronic steroid use or known collagen synthesis disturbance such as Ehlers Danlos disease also cause rupture uterus.

Clinical signs of uterine rupture in early pregnancy are non-specific. Abdominal pain, vaginal bleeding and vomiting are classic findings. Differential diagnosis are bleeding corpus luteum, heterotopic or ectopic pregnancy and molar pregnancy with secondary invasion. ${ }^{5}$ Sometimes ultrasound may have limited value and emergency surgery is needed to prevent catastrophic sequelae.

\section{CONCLUSION}

We report this case to highlight the fact that although rupture uterus is a very rare complication in primigravida, it can happen and should be kept in mind during diagnosis and treatment of shock in pregnancy regardless of parity.

\section{Funding: No funding sources \\ Conflict of interest: None declared \\ Ethical approval: Not required}

\section{REFERENCES}

1. Jaju PB, Bidri SR, Sangamesh M, Ashwini V. Spontaneous rupture of the uterus in primigravida: a case report. J Med Medic Res. 2014;2(1):1-5.

2. Sinha P, Agrawal NR. Spontaneous uterine rupture in first trimester of pregnancy. Int $\mathrm{J}$ Reprod Contracept Obstet Gynecol. 2014;3(3):831-2. 
3. Park YJ, Ryu KY, Lee J, Park M. Spontaneous Uterine Rupture in the First Trimester: A Case Report. J Korean Med Sci. 2005;20:1079-81.

4. Gibbins KJ, Weber T, Holmgren CM, Porter TF, Varner MW, Manuck TA. Maternal and fetal morbidity associated with uterine rupture of the unscarred uterus. Am J Obstet Gynecol. 2015;213:382.
5. Tola EN. First trimester spontaneous uterine rupture in a young woman with uterine anomaly. Case reports in Obstet and Gynecol; 2014.

Cite this article as: Das Ghosh M, Singh V. Spontaneous uterine rupture in Primigravida at 15 weeks. Int J Reprod Contracept Obstet Gynecol 2017;6:1138-40. 